\title{
Maintenance of avoidance during differential shock and nonshock confinement'
}

JAMES H. REYNIERSE, ROSS RIZLEY, and MICHAEL J. SCAVIO, JR., ${ }^{2}$ University of Nebraska at Lincoln, Nebr.

Acquisition and extinction of rat avoidance was unaffected by relative shock and nonshock compartment confinement and retention of avoidance, although statistically significant, was an impotent factor for the Holtzman strain, but a potent factor for Sasco rats. In general, Holtzman rats were more resistant to extinction than Sasco rats.

A number of studies originating at Michigan State University with Denny and his associates indicate that long nonshock confinement controls speed of acquisition and extinction of simple avoidance learning tasks. Acquisition (Reynierse, Weisman, \& Denny, 1963; Denny \& Weisman, 1964; Weisman, Denny, \& Zerbolio, 1967; Zerbolio, 1968) and extinction (Denny \& Weisman, 1964; Weisman, Denny, Platt, \& Zerbolio, 1966) were facilitated by long confinement in the discriminable safe compartment of what are essentially one-way avoidance tasks. Analyses of these effects in terms of elicitation theory (Denny \& Adelman, 1955; Denny, 1967) emphasizes that long nonshock confinement permits conditioning of relaxation to stimuli in the nonshock area. In addition to mediating the acquisition of avoidance, the chaining or generalization of relaxation to the shock area presumably provides competing responses mediating extinction of avoidance.

These results are unequivocal and reproducable when strain of rat, like the Michigan State University strain, is characterized by a long latency relaxation response. But in less emotional, more docile strains, relaxation may be a relatively short latency response and length of nonshock compartment confinement may be less important. There is some support for this since nonemotional Holtzman rats show high resistance to extinction under many experimental conditions while a more emotional strain extinguished quickly (Reynierse, 1968).

\section{EXPERIMENT 1}

The present investigation examines acquisition and extinction of avoidance as a function of relative shock and nonshock compartment confinement. In addition, retention of avoidance was investigated for a short and long delay.

Subjects

The Ss were 80 adult, male albino rats of the Holtzman strain. Maintained three to five Ss per cage, with food and water always available, Ss were assigned at random to 10 groups of eight Ss each.

Apparatus

The apparatus consisted of a one-way box having two discriminable compartments separated by a manually operated guillotine door. The shock compartment was painted flat black and had a grid floor consisting of $1 / 8 \mathrm{in}$. stainless steel grids spaced $5 / 8$ in. apart, center to center. Shock of $1.0 \mathrm{~mA}$ was delivered to the grids by a Grason-Stadler shocker-scrambler, Model E1064GS. The nonshock compartment was painted white and had a wooden floor. A $60 \mathrm{~dB}$ transistorized buzzer (Malis \& Curran, 1960) and the raising of the guillotine door served as the CS. A speaker mounted on the Plexiglas top of the shock compartment delivered the auditory CS directly into the shock compartment.

Procedure

For all Ss in all conditions the intertrial interval was fixed at 120 sec. The CS-US interval was $5 \mathrm{sec}$, both CS and US being response terminated. All Ss ran initially to an acquisition criterion of two successive avoidances.

Groups were differentiated in terms of both acquisition and extinction conditions. During acquisition, $S$ was confined in the shock compartment for $20,40,60,80$, or $100 \mathrm{sec}$, the remainder of each intertrial interval being spent in the nonshock compartment. Extinction was begun after either a 5-min or 24-h delay with shock and safe compartment confinement conditions identical with those during acquisition. Thus, the experimental design during extinction consisted of a 5 by 2 factorial design with eight Ss per cell in which five levels of shock compartment confinement were orthogonal to two retention intervals.

Delay periods prior to extinction were spent in S's home cage. When $S$ was removed from its home cage following this delay, $S$ was always placed in the nonshock compartment before being placed in the shock compartment. Extinction was considered to be complete when $S$ failed to respond to the CS for a $60 \mathrm{sec}$ period on two successive trials. When $S$ did not respond to the CS, S remained in the shock compartment for $120 \mathrm{sec}$ until the next trial was administered.

Results

Analysis of variance for the simple effects of confinement during acquisition were not significant $(F=1.59)$. Figure 1 summarizes the mean trials to extinction as a function of confinement and delay conditions. Only the effect for delay was significant $(\mathrm{F}=4.27, \mathrm{df}=1 / 70, \mathrm{p}<.05)$. Although inspection of Fig. 1 suggests that confinement effects are large, they are in fact nonsignificant both as a main effect and in interaction $(F<1)$.

Although extinction was more rapid after a $24 \mathrm{~h}$ delay than after $5 \mathrm{~min}$, the differences are relatively small. Indeed, the most conspicuous effect of this research was the relatively high resistance to extinction obtained for all conditions. The potency of the delay effect was measured by a variance component analysis (Green \& Tukey, 1960) which estimates the population variance associated with a significant factor. The delay variance was 70.52 , only $8 \%$ as large as the experimental error variance (864.01), clearly showing the impotency of the delay factor.

\section{EXPERIMENT 2}

In Experiment 1, nonshock confinement did not influence speed of acquisition or extinction of a simple, one-way avoidance learning task, results which contrast with those coming from the Michigan State University laboratory but that

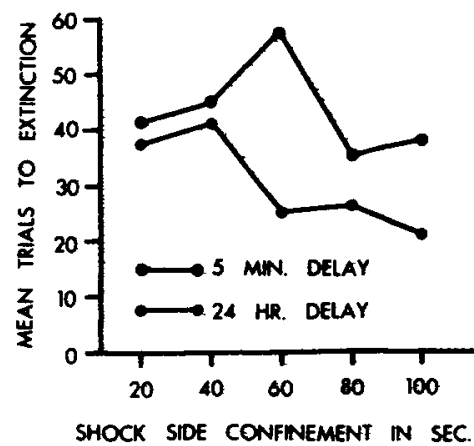

Fig. 1. Mean number of trials to extinction as a function of relative shock and nonshock confinement for both delay conditions for Holtzman rats. 


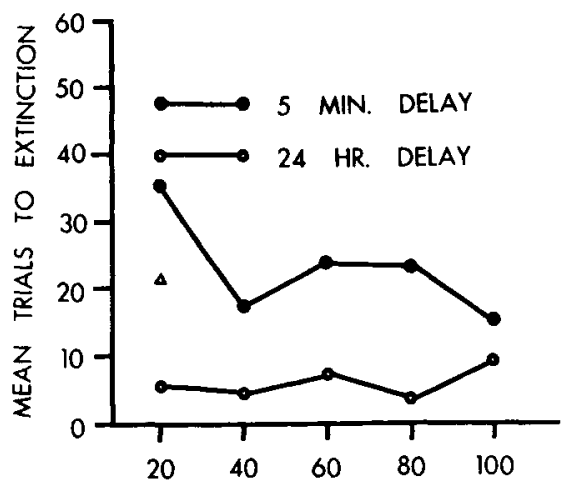

SHOCK SIDE CONFINEMENT IN SEC.

Fig. 2. Mean number of trials to extinction as a function of relative shock and nonshock confinement for both delay conditions for Sasco rats. The $\Delta$ data point represents performance from a comparable $20 \mathrm{sec}$ shock confinement condition (Reynierse, 1968).

are consistent with our own research when nonemotional Holtzman rats are used (Reynierse, 1968). These differences may be due to strain of rat, i.e., long nonshock confinement may control acquisition and extinction of avoidance only when relaxation is a long latency response. Strains of rat characterized by a short latency relaxation response may maximize the opportunity for relaxation-produced stimuli to be conditioned to avoidance so that these same relaxationproduced stimuli elicit and maintain avoidance responding during extinction procedures (Reynierse, 1966). This experiment replicates the procedure of Experiment 1 but with a different, more emotional strain of rat.

Subjects

The Ss were 80 adult, male albino rats of the $\mathrm{Sasco}^{3}$ strain and maintained as in Experiment 1.

Procedure

Apparatus and procedure were identical to that of Experiment 1 , the only difference being strain or rat. Thus, the experimental design during extinction was a 5 by 2 factorial design in which five levels of shock compartment confinement $(20,40$, $60,80$, or $100 \mathrm{sec})$ were orthogonal to two retention intervals (5-min or 24-h). Each confinement condition was assigned 10 Ss for the 5-min delay and six Ss for the 24-h delay.

Results

Analysis of variance for the simple effects of confinement during acquisition were not significant $(F=1.85)$. Figure 2 summarizes the mean trials to extinction as a function of confinement and delay conditions. Only the effect for delay was significant $(\mathrm{F}=17.9, \mathrm{df}=1 / 70, \mathrm{p}<.01)$. Although it appears that $20 \mathrm{sec}$ shock confinement produced greater resistance to extinction than other confinement conditions, all confinement effects were nonsignificant. Examining the perfomance of Sasco rats in an identical $20 \mathrm{sec}$ shock confinement group, but from another experiment (Reynierse, 1968), showed less deviant performance and was equivalent to that of the other four confinement groups.

In contrast to Experiment I where significant delay effects were small. large effects were obtained in the present experiment. The potency of the delay effect was again measured by a variance component analysis, but this time the delay factor was clearly potent as the delay variance was $131.4,45 \%$ as large as the experimental error variance (291.25).

Comparing the performance of the two strains for each delay condition indicates that Holtzman rats are more resistant to extinction regardless of delay. Disregarding confinement conditions, Holtzman rats extinguished in 43.65 trials while Sasco rats extinguished in 22.6 trials for the 5 -min delay $(t=4.119, \mathrm{df}=39, \mathrm{p}<.001)$; for the 24-li delay Holtzman and Sasco rats extinguished in 29.98 and 5.97 trials, respectively $(t=4.86$, $\mathrm{df}=29, \mathrm{p}<.001)$.

Discussion

That nonemotional Holtzman rats show higher levels of resistance to extinction than the emotional Sasco strain is consistent with earlier research (Reynierse, 1968), and illustrates the importance of the strain variable. But the failure to find confinement effects during acquisition and extinction is of greater interest. In view of the frequency with which confinement effects have been previously reported, such a failure is surprising, but not necessarily paradoxical. Nor is it necessarily inconsistent with the elicitation or relaxation model (Denny, 1967). Thus, any number of variables distinguishing these studies from earlier research and including strain differences, confinement procedures, intertrial interval and the measure of performance, could presumably account for these differences. What is apparent, however, is that we know surprisingly little about the effects of relative shock and nonshock confinement in which intertrial interval is constant and shock and nonshock compartment confinement covary.

\section{REFERENCES}

DENNY, M. R. A learning model. In W. C. Corning and S. C. Ratner (Eds.), Chemistry of learning. New York: Plenum Press, 1967. Pp. 32-42.

DENNY, M. R., \& ADELMAN, H. M. Elicitation theory: I. Analysis of two typical learning situations. Psychological Review, 1955, 62, 290-296.

DENNY, M. R., \& WEISMAN, R. G. Avoidance behavior as a function of the length of nonshock confinement. Journal of Comparative \& Physiological Psychology, 1964, 58, 252-257.

GREEN, B. F., \& TUKEY, J. Complex analysis of variance: General problems. Psychometrika, 1960, 25, 127-152.

MALIS, J. L., \& CURRAN, C. S. A reliable low-cost generator for audio stimuli. Journal of Experimental Analysis of Behavior, 1960, 3, 200.

REYNIFRSE, J. H. Effects of CS only trials on resistance to extinction of an avoidance response. Journal of Comparative \& Physiological Psychology, 1966, 61, 156-158.

REYNIERSE, J. H. Strain differences in continued avoidance after a short or long delay. Psychological Reports, 1968, 23, 143-148.

REYNIERSE, J. H., WEISMAN, R. G., \& DENNY, M. R. Shock compartment confinement during the intertrial interval in avoidance learning. Psychological Record, 1963, 13, 403-406.

WEISMAN, R. G., DENNY, M. R., PLATT, S. A., \& ZERBOLIO, D. J. Facilitation of extinction by a stimulus associated with long nonshock confinement periods. Journal of Comparative \& Physiological Psychology, 1966, 62, 26-30.

WEISMAN, R. G., DENNY, M. R., \& ZERBOLIO, D. J. Discrimination based on differential nonshock confinement in a shuttlebox. Journal of Comparative \& Physiological Psychology, 1967, 63, 34-38.

ZERBOLIO, D. J. Escape and approach responses in avoidance learning. Canadian Journal of Psychology, 1968, 22, 60-71.

$$
\text { NOTES }
$$

1. This research was supported by research Grants MHI2716-01 and MH12716-02 from the National Institute of Mental Health.

2. Now at the State University of Iowa.

3. Sasco rats were obtained from Sasco, 5309 N. 24th Street, Omaha, Nebraska. 